\title{
DEVELOPMENT OF THE DESIGN AND DETERMINATION OF MODE CHARACTERISTICS OF BLOCK CRYOCONCENTRATORS FOR POMEGRANATE JUICE
}

\author{
O leg Burdo \\ Doctor of Technical Sciences, Professor* \\ I gor Bezbakh \\ Doctor of Technical Sciences, Associate Professor* \\ E-mail: igorbezbakh1003@gmail.com \\ Aleksandr Zykov \\ Doctor of Technical Sciences* \\ Yana Fatieieva \\ Postgraduate Student* \\ Davar Rostami Pour \\ Director \\ Firm «Davarrostamipour» \\ Shahid Bahonar str., 13, Tehran, Iran \\ Pet r Os ad chuk \\ $\mathrm{PhD}$, Associate Professor \\ Department of Agricultural Engineering \\ Odessa State Agrarian University \\ Pantelyimonivska str., 13, Odessa, Ukraine, 65012 \\ I gor Mazurenko \\ Doctor of Technical Sciences, Professor \\ Hunan University of Humanities, Science and Technology \\ Dixing Road str., 487, Loudi, Hunan Province, China, 417000 \\ S hao Zhengzheng \\ Postgraduate Student \\ School of Food Science \\ Henan Institute of Science and Technology \\ Hualan Road str., 90, Xinxiang, China, 453003 \\ Lyudmila Phylipova \\ Director \\ Organic Products \\ Vysokiy lane, 13, Odessa, Ukraine, 65007 \\ *Department of Process, Equipment and Energy Management \\ Odessa National Academy of Food Technologies \\ Kanatna str., 112, Odessa, Ukraine, 65039
}

Research and Planning Institute of Standardisation and Technology of Ecosafe and

Received date 06.03.2021 Accepted date 16.04.2021 Published date 30.04.2021
How to Cite: Burdo, O., Bezbakh, I., Zykov, A., Fatieieva, Y., Pour, D. R., Petr, O., Mazurenko, I., Zhengzheng, S., Phylipova, L. (2021). Development of the design and determination of mode characteristics of block cryoconcentrators for pomegranate juice. Eastern-European Journal of Enterprise Technologies, 2 (11 (110)), 6-14. doi: https://doi.org/10.15587/1729-4061.2021.230182

\section{Introduction}

Concentrating fruit juices is one of the oldest methods that can significantly extend the shelf life of fresh produce.

In principle, there are 3 ways to solve the problem of removing water from a solution. The first is the conversion of water into steam with subsequent removal of steam. The second is the mechanical separation of water using semi-permeable membranes. The third is the transformation of water into a solid phase and its removal in the form of ice.
Most food solutions are evaporated under vacuum, which allows the boiling point to be reduced to $40 \ldots 60^{\circ} \mathrm{C}$.

Thermally concentrating fruit juices has an adverse effect on their organoleptic and chemical properties. Some juices, such as citrus fruits, are especially sensitive to heat.

Darkening is caused by an intermediate product, oxymethylfurfural, formed in the presence of sugars and acid. During evaporation, valuable aromatic substances are lost, which are important for the quality of juices. 
Despite the simplicity of the evaporation technique, these technologies cannot be considered as meeting modern requirements for food quality, especially for pomegranate juice.

Evaporation technologies are energy intensive. Evaporation consumes from $2.8 \times 10^{6} \mathrm{~kJ}$ per 1 ton of evaporated water (one-stage process) to $0.85 \times 10^{5} \mathrm{~kJ}$ per 1 ton (multistage process).

The advantages of reverse osmosis include: low energy costs; improving the quality of the concentrate due to the low process temperature; good sanitary conditions of production. All this is explained by the fact that membrane technology does not require energy consumption for phase transformations of water. Maximum by reverse osmosis can achieve a concentration of $30 \ldots 40 \%$ of dry substances. It is ineffective to achieve a higher concentration, since this requires high pressures, power consumption and large installations. Also, the low introduction of membrane technologies is associated with an insufficient range and quality of membranes produced by the industry, installations for membrane processes.

Cryoconcentration technology is presented as a suitable technology for concentrating liquid foodstuffs because it can preserve the nutritional and sensory qualities of foods.

The basic scheme of the block freezing method developed at the Odessa National Academy of Food Technologies is protected by a patent [1]. The essence of the invention is that cooled rod crystallizers are immersed in a container with a pre-cooled product, on the surface of which blocks of ice are frozen. Then they are removed from the container and kept in air at a positive temperature. Collect the solution flowing down from the block and return it for further concentration. The very holding of the block is carried out until a predetermined value of dry substances is reached in the flowing solution, which is determined by the permissible losses of dry substances in the molten block.

\section{Literature review and problem statement}

According to various researchers [2,3], there are two main methods for the formation of ice crystals in solutions. The first is known as the crystallization of a solution in the form of an ice slurry. The second method is the crystallization of water present in the solution in the form of a layer of ice on a cold surface.

In almost all crystallization equipment, there are moving parts in the form of an ice slurry. In such equipment, it is possible to implement a continuous process. For the implementation of the second method, film and block crystallizers are used. Film crystallizers are mainly of batch type [4]. One of the advantages of the film crystallization method is its simplicity in terms of equipment design and operation.

Studies No. 5, 6 show that the final juice concentrations when using an ice slurry vary between $35^{\circ}$ Brix and $55^{\circ}$ Brix. With film freezing of juices, the maximum achieved concentrations are about $28^{\circ}$ Brix [7], with sugar solutions $50^{\circ}$ Brix [8].

In work No. 9, a model of the kinetics of film freezing of apple juice was developed. Research results show that the kinetics of the process corresponds to a sigmoidal curve. Similar results can be found in Ref. 10 for cryoconcentration of lime juice. In work No. 11, film freezing of sucrose solu- tions was studied. The kinetics of the process corresponded to a linear function.

Analysis of works No. 5-11 shows that studies of the kinetics of freezing of pomegranate juice by various methods have practically not been carried out. Perhaps this is due to the fact that producers of pomegranate juice prefer thermal and mechanical (membrane) concentration methods as more productive.

Research using juices pursues a wide range of tasks, including studying the basis of the process and determining the organoleptic qualities of the obtained juices. Basically, research [5-11] is aimed at obtaining the most pure ice without inclusions of dry substances contained in juices.

Since pomegranate juice is a valuable source of biologically active compounds responsible for its appropriate color, the cryoconcentration process has a high potential to preserve its nutritional and sensory properties.

Pomegranate juice is classified as a fruit juice with high antioxidant activity. Juice and processed products of pomegranate are used as a component for various food products [12-14].

A wide range of research has been devoted to thermal concentration methods. In work No. 15, clarified pomegranate juice was concentrated at atmospheric pressure, under the action of microwave radiation, and in a rotary vacuum evaporator. Final juice concentration $65^{\circ}$ Brix. The rotary vacuum evaporator ensures the production of juice concentrate with maximum preservation of quality parameters (anthocyanins $321.97 \mathrm{mg} / 100 \mathrm{~g}$, antioxidant activity $76.41 \%$ ).

In work No. 16, pomegranate juice containing $17.5 \%$ of the total soluble solids was evaporated to $40^{\circ}$ Brix. The process was carried out under vacuum and ohmic heating conditions. The color properties of pomegranate juice concentrates evaporated using ohmic heating were more affected than those that were evaporated using an evaporation vacuum.

In work No. 17, pomegranate juice was concentrated using a microwave field in a rotary vacuum evaporator and heating at atmospheric pressure. The final juice concentration of $60.5^{\circ}$ Brix was reached after 23, 108 and 190 minutes, respectively. It was noted that the degree of color loss was higher during the vacuum heating process.

The advantage of the methods discussed in [15-17] is the high speed of the process, the disadvantage is the loss of quality indicators of nutritional value and appearance of pomegranate juice [18]. In addition, concentration by freezing is less energy intensive, since the heat of ice formation is approximately 8 times less than the heat of vaporization.

A large number of studies are devoted to systems of capacitive (block) freezing, methods of intensifying the process of separating substances from an ice block.

In work [19], the process of block cryoconcentration of apple juice, frozen blueberry and pineapple juices was investigated. Centrifugation was used as an auxiliary method in the separation process. The concentration is increased by about 2.5 times the initial solids concentration.

In work No. 20, a study of block freezing under vacuum $(40 \mathrm{kPa})$ of a wine sample was carried out. The initial concentration was $8^{\circ}$ Brix, the process was carried out for 5 minutes, the sample volume was $45 \mathrm{ml}$. The final concentration of the sample is $50^{\circ}$ Brix. As a result, $\mathrm{pH}$, alcohol content, acidity and total polyphenols were significantly increased compared to fresh wine. The color rating indicates that the concentrate was darker than the original sample. 
In [21], block cryoconcentration of pomegranate juice was studied at freezing temperatures $\left(-20 \pm 1{ }^{\circ} \mathrm{C}\right.$ and $\left.-40 \pm 1{ }^{\circ} \mathrm{C}\right)$. It is shown that the acidity of cryoconcentrated pomegranate juice is lower than that of thermally obtained concentrates. The color characteristics of pomegranate juice are well preserved in the block cryoconcentration process compared to traditional thermal processes. The freezing temperature and the thawing mode did not significantly affect the total dry matter content of the cryoconcentrated and ice fractions, as well as the process efficiency, $\mathrm{pH}$ and color values. The final dry matter content in the pomegranate concentrate was $34.20 \pm 0.13 \%$ of the initial value of $17.16 \pm 0.68 \%$.

Experiments [15-21] are mainly aimed at studying qualitative characteristics - color, acidity, antioxidant activity. The operating characteristics of units for block freezing have been little studied.

Block freezing experiments were carried out for juices [19], wines [20]. In terms of pomegranate juice, studies were mainly carried out on thermal concentration methods [15-17], in block freezing it is not enough. In works [18-20], studies were carried out on small volumes $(45 \ldots 50 \mathrm{ml})$, which would complicate the results of scaling up to an industrial installation. In study [21] for pomegranate juice, studies were carried out in a narrow temperature range.

The block cryoconcentration process is still mainly investigated in laboratory conditions. There are small industrial plants with a maximum capacity of about 50 liters. Larger scale units $(100 \mathrm{~L})$ are under development [11]. Scaling this technology to an industrial scale requires a deeper understanding of the dynamics of the process, which requires both experimental and model work.

Lowering the operating temperature of the refrigeration unit promotes more intensive growth of the ice block. At the same time, the required power of the refrigerating machine increases, the porosity of the ice block increases. The separation degree of the solution is reduced. The study of these contradictions is the task of complex, complex thermophysical research.

For the development of industrial plants, it is necessary to study the kinetics of ice block formation, the effect of the initial juice concentration, the boiling point of freon on the specific volumetric productivity of the crystallizer, the kinetics of the pomegranate juice concentration, and the kinetics of the ice block separation process. Research is needed for pomegranate juice and compare the models with those obtained in studies [9-11]

\section{The aim and objectives of research}

The aim of research is to develop designs and determine the operating parameters of block cryoconcentrators for pomegranate juice. As a result, an increase in the degree of juice concentration, a decrease in product losses, the preservation of the food potential of raw materials, and savings in transportation are expected. The data obtained can be used for further development and creation of industrial plants with optimal improved product parameters.

To achieve the aim, the following objectives were set:

- to conduct experimental studies of the kinetics of ice block formation;

- to study the kinetics of block cryoconcentration of pomegranate juice;

- to study the kinetics of the ice block separation process;

- to generalize the results of experimental modeling.

\section{Materials and methods for studying the process of} block cryoconcentration of pomegranate juice

Experimental studies were carried out on two stands BV-2 and BL-20, developed at the Department of Processes, Equipment and Energy Management of the Odesa National Academy of Food Technologies (Ukraine). The research program was the same in the experiments. Mode of operation is regular removal of energy by means of a refrigeration machine from the volume of juice that was poured into the concentrator. The following were measured periodically: the temperatures of the solution, the surface of the ice block, the volume of liquid and its concentration, the thickness of the ice block, and the boiling point of freon in the crystallizer.

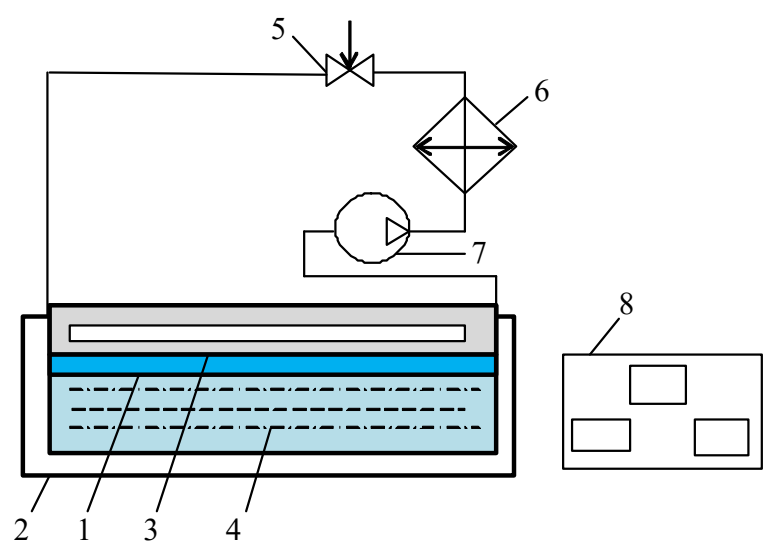

Fig. 1. Scheme of the BV-2 unit: 1 - ice layer, 2 - concentrator, 3 - crystallizer, 4 - product, 5 - throttle valve, 6 - air condenser, 7 - compressor, 8 - instrument block

Pre-cooled pomegranate juice is poured into concentrator 2, which is made of organic glass. The concentrator is autonomous, has a rectangular shape, can be moved vertically and horizontally. The concentrator is not structurally connected with the rest of the stand elements.

The slipway with the concentrator rises until the product touches the surface of the crystallizer 3 , which is located in the center of the concentrator. Crystallizer 3 has a rectangular shape. On the surface of the mold 3 , a layer of ice 1 is formed, which eventually turns into a block.

The stand is equipped with a refrigerating machine consisting of a control throttle valve 5 , an air condenser 6 and a compressor 7 . The electrical power consumed by the machine is measured by an instrument unit 8 . The temperatures of the crystallizer, ice and juice surface are measured with a FLIR TG54 thermal imaging pyrometer, the measurement range of which is from 30 to $650{ }^{\circ} \mathrm{C}$, the measurement accuracy is $1 \%$. In experiments on the BV-2 installation, 1.5 liters of pomegranate juice were poured into the concentrator.

The second stand (BL-20) had a slipway, which, using a worm gear, moved concentrator 2 vertically (Fig. 2).

On the control panel (Fig. 2, $b$ ) there are start-stop buttons, a pressure gauge showing the boiling pressure of R-22 freon in crystallizer 3 and a freeze-defrost mode switch.

Crystallizer 3 is made in the form of stainless steel plates 2 . Refrigerant movement channels are made in the gap between the plates by means of contact welding. At the top, the crystallizer was connected through the fittings to the refrigerating machine, the capacity of which was regulated by valve 5 . The 
original design of the crystallizer ensured an efficient ice formation process and simple removal of the ice block in defrost mode.

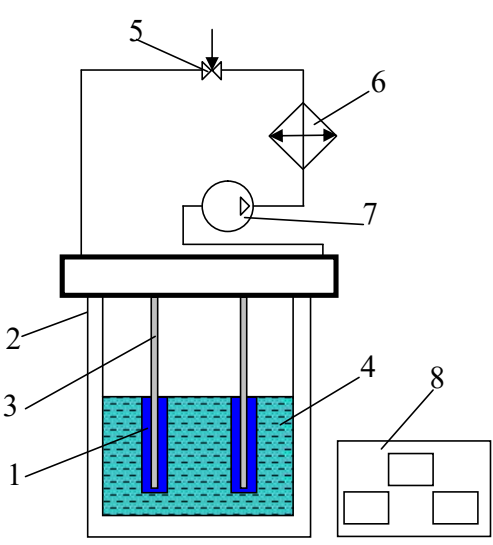

$a$

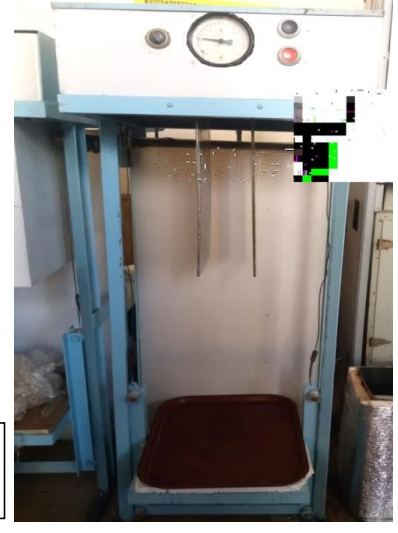

$b$
Fig. 2. Experimental model of BL-20 block freezing unit: $a$ - diagram; $b$ - photo; 1 - block of ice; 2 - concentrator; 3 - crystallizer; 4 - product; 5 - regulating throttle valve; 6 - capacitor; 7 - compressor; 8 - block of measuring devices

Concentrator capacity - 201 of liquid. The research program included periodic recording of the temperatures of the solution, the ice block and the surface of the crystallizer. Temperature measurements were carried out using thermocouples and a combined digital instrument W-300, a FLIR TG54 pyrometer. The volume of liquid in the concentrator and the thickness of the ice block were measured. The juice concentration was determined using a digital TDS-meter Hanna Dist 3. The boiling point of freon in the crystallizer was determined using a manovacuum meter (Fig. 2, $b$ ).

The set of measuring equipment made it possible to study the effect of juice concentration, its volume, temperature and design parameters on the kinetics of ice formation, the structure of liquid and solid phases, and the degree of concentration of the solution. After the end of the freezing process, the installation was switched to the "defrost" mode, the hot freon vapor entered the crystallizer, and the block of ice was removed from the surface of the crystallizer. The block of ice was fed to gravity separation.

The plants have different concentra-

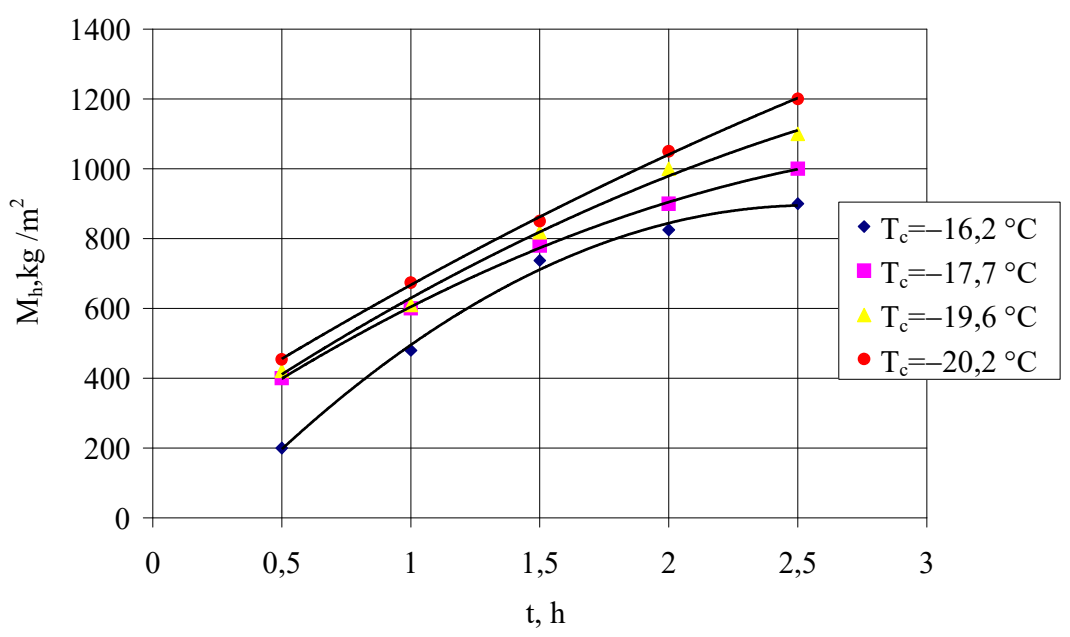

Fig. 3. Kinetics of ice block formation on the horizontal crystallizer BV-2, depending on the temperature of the coolant: $M_{h}-$ specific productivity, $\mathrm{kg} / \mathrm{m}^{2}$; $T_{c}-$ coolant temperature tor volumes and crystallizer designs. In the first unit (BV-2) the volume of the product is $2 \mathrm{~kg}$, and the crystallizer is installed horizontally (Fig. 1). This arrangement of the mold has the following advantages:

- vertical channels are formed in the volume of the ice block, from which juice is more efficiently evacuated during the separation process;

- location of the crystallizer at the top of the solution initiates gravitational convective currents, which has a positive effect on the processes of heat and mass transfer.

The disadvantage of the BV-2 design is that only one side of the mold surface is used and it is difficult to assemble a system of such molds in one apparatus. Thus, the installation (Fig. 1) is limited to small capacities.

\section{Results of experimental studies of the process of block cryoconcentration of pomegranate juice}

\section{1. Results of experimental studies of the ice} block formation process

An ideal solution separation process requires an infinitely low driving force, i.e., a temperature equal to the cryoscopic value. Under these conditions, a solid phase with a dense packing of crystals without pores is formed, which ensures ideal separation of the solution. However, such a process will continue indefinitely. Thus, the temperature of the organization of the process is a factor that reflects the scientific and technical contradiction of technology. The lower the process temperature, the faster the ice block is formed, but the greater the required capacity of the refrigeration machine, the greater the porosity of the ice block, the worse the degree of solution separation. Ambiguous dependence of temperature on the amount of energy consumed. The study of these contradictions is the task of complex, complex thermophysical research.

The results of experiments on the kinetics of ice block formation are shown in Fig. 3 .

Lowering the operating temperature of the refrigeration unit promotes more intensive growth of the ice block and a decrease in the amount of concentrated solution (Fig. 3). When the temperature of the coolant decreases by 1.2 times, the productivity increases by 1.3 times. 


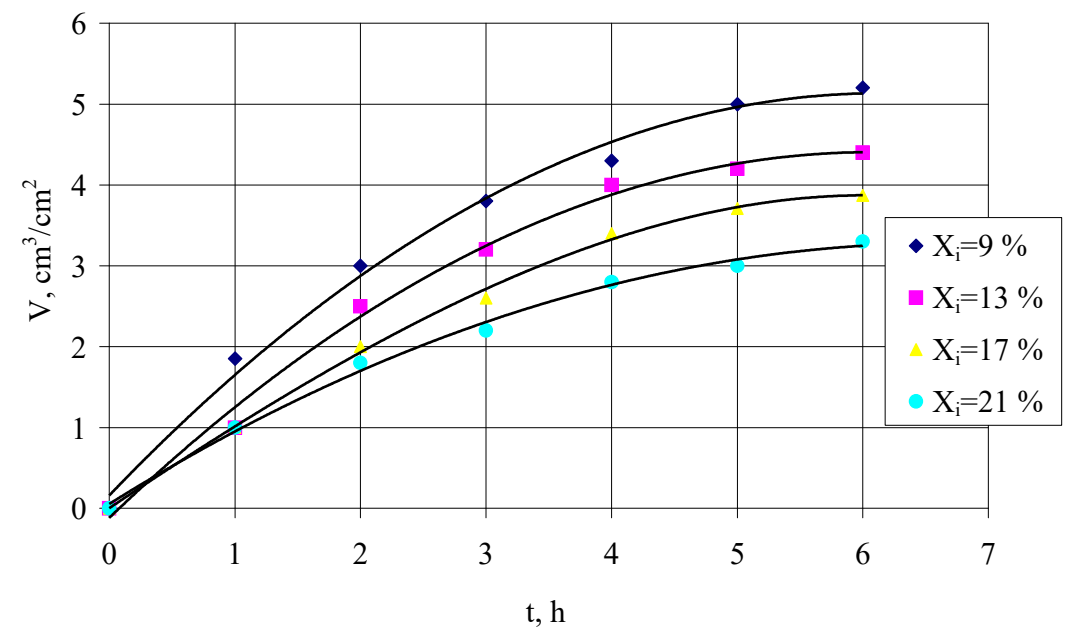

Fig. 4. Influence of the initial juice concentration on the specific volumetric productivity of the BL-20 crystallizer: $X_{i}-$ the initial juice concentration; $V$ - specific volumetric productivity, $\mathrm{cm}^{3} / \mathrm{cm}^{2}$
In the entire range of operation, a decrease in the boiling point of freon by $1{ }^{\circ} \mathrm{C}$ led to an increase in the productivity of the apparatus by $1 . . .3 \%$ (Fig. 5 ). At the same time, the boiling point of freon has a complex effect on the concentration of the solution, on the structure of the ice block, and on the energy consumption of the technology.

5. 2. Results of experimental studies of the kinetics of block cryoconcentration of pomegranate juice

The influence of the initial concentration of juice for the BL-20 crystallizer is investigated (Fig. 6).

With an increase in the initial concentration of the model solutions, the growth rate of the ice block decreases.

The data (Fig. 6) show that if at the initial concentrations for 5 hours the dry matter content in the juice increases by $16 \%$, then at the highest concentrations - only by $4 \%$.
An increase in concentration by 3 times leads to a decrease in productivity by 2.5...1.5 times (Fig. 4). Moreover, over time, the intensity of ice formation decreases, although it remains acceptable in the entire range of experiments.

An important factor that influences the rate of ice block formation is the surface temperature of the mold. In practice, this temperature corresponds to the boiling point of the refrigerant in the channels of the crystallizer. This temperature was determined by a pressure gauge, according to the vapor pressure of $\mathrm{R}-22$ freon in front of the compressor.

The kinetics of ice formation for the BL-20 crystallizer was studied on juice, the concentration of which corresponded to the initial value $\left(13^{\circ}\right.$ Brix $)$. The boiling point of $\mathrm{R}-22$ varied from $-15{ }^{\circ} \mathrm{C}$ to $-18{ }^{\circ} \mathrm{C}$ (Fig. 5 ).

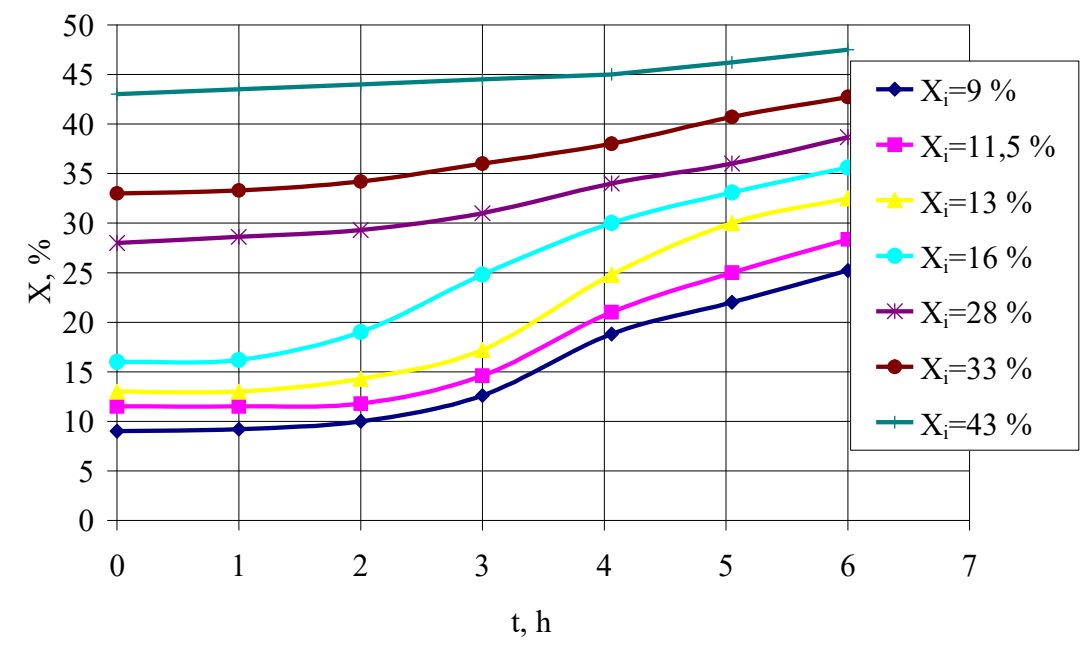

Fig. 6. Influence of the initial concentration on the kinetics of the concentration of pomegranate juice for the BL-20 crystallizer: $X_{i}$ is the initial concentration of juice

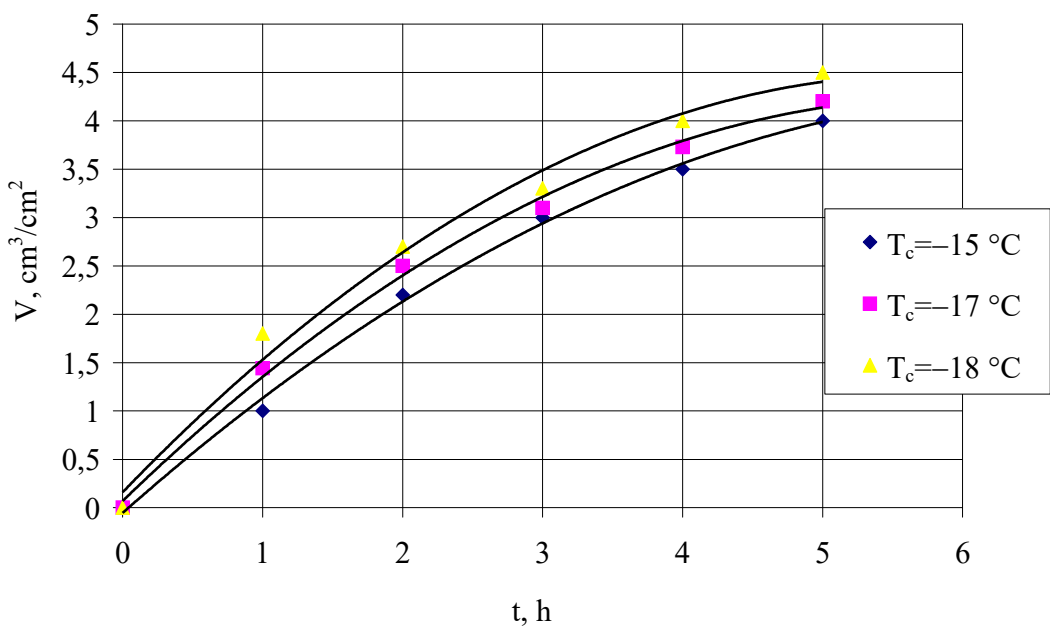

Fig. 5. Kinetics of ice block formation at different boiling temperatures of R-22 for the BL-20 crystallizer: $T_{c}$ - coolant temperature;

$V$ - specific volumetric productivity, $\mathrm{cm}^{3} / \mathrm{cm}^{2}$
The maximum concentration of pomegranate juice of $47^{\circ}$ Brix is reached at an initial concentration of $43^{\circ}$ Brix (Fig. 6).

At low initial concentrations, the curves repeat the shape of the sigmoidal curve as in studies [9, 10]; with increasing concentration, the curve tends to a linear function.

The effect of the crystallization temperature on the kinetics of the growth of the juice concentration was investigated (Fig. 7). The experiments were carried out with juice, the initial concentration of which was $13 \%$.

Within 2 hours, the temperature of the coolant does not affect the change in the concentration of the solution (Fig. 7).

The results obtained were compared with the data on cryoconcentration of cherry juice [22], which are shown in Fig. 8. For comparison, cherry juice was selected as close in dry matter content $(15 \% / 17 \%)$, dietary fiber (0.4/0.2 g/100 g), ash (0.4/0.3 g/100 g). 


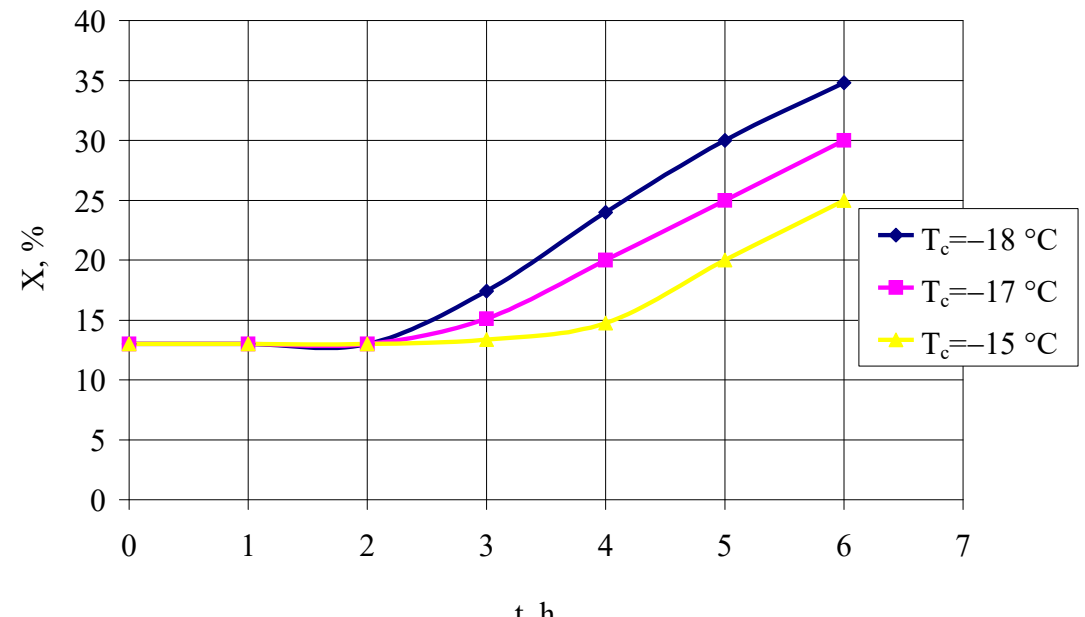

Fig. 7. The increase in the concentration of pomegranate juice depending on the temperature of the coolant

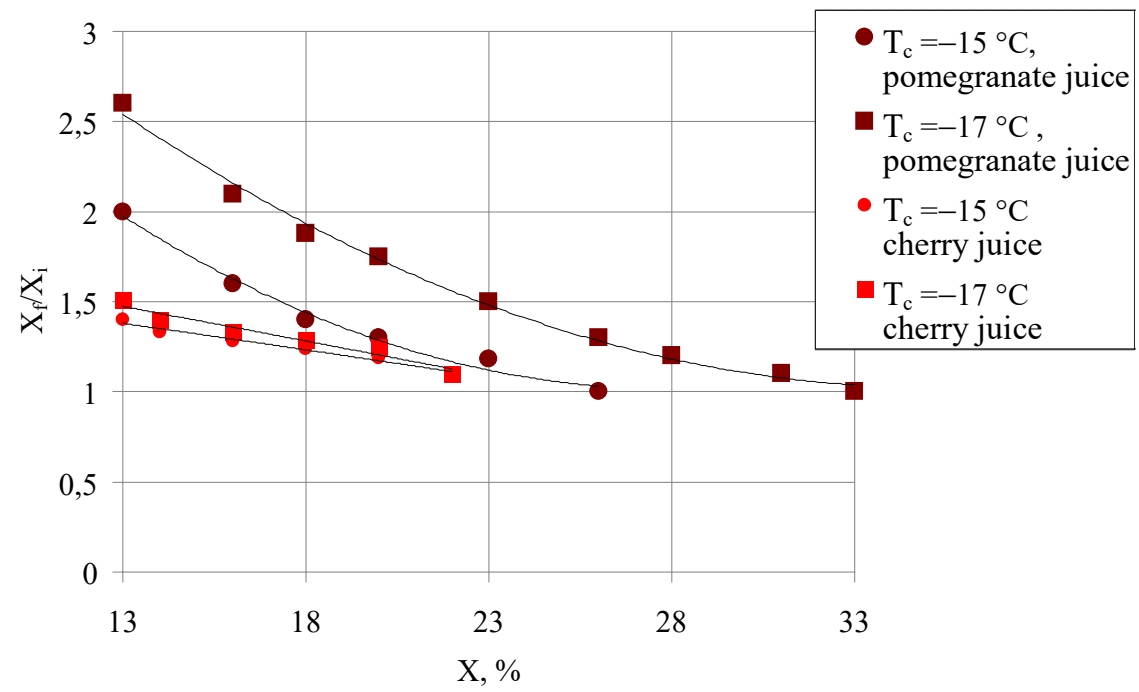

Fig. 8. Comparison of the concentration degree of cherry and pomegranate juice

At practically the same initial concentrations, in experiments with cherry juice, the limiting concentrations of the product reached $22 \%$, and with pomegranate juice, $47 \%$.

Comparison shows:

1) at a crystallizer temperature of $-15^{\circ} \mathrm{C}$, the degree of increase in the concentration of cherry juice was 1.4, and of pomegranate juice 2 (Fig. 8);

2) at a crystallizer temperature of $-18{ }^{\circ} \mathrm{C}$, the degree of increase in the concentration of cherry juice was 1.51 , and pomegranate juice 2.6 (Fig. 8).

\section{3. Kinetics of ice block separation process}

The structure of the ice block depends significantly on the concentration of the solution. Photographs of the ice block surface after its separation (Fig. 9, $b$ ) indicate a dense packing of crystals, about the possibilities of effective evacuation of juice from the ice volume.

The structure of ice is formed in the form of complex scaly "branches" with the formation of radial and vertical channels (Fig. 9, $a$ ). In the process of separation, the structure retains its shape well and allows the contents of the channels to be evacuated.

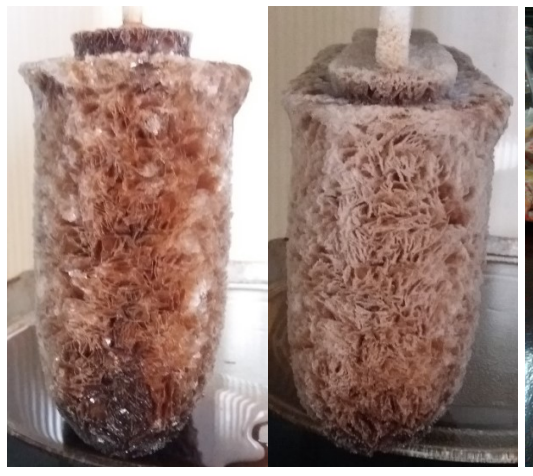

$a$

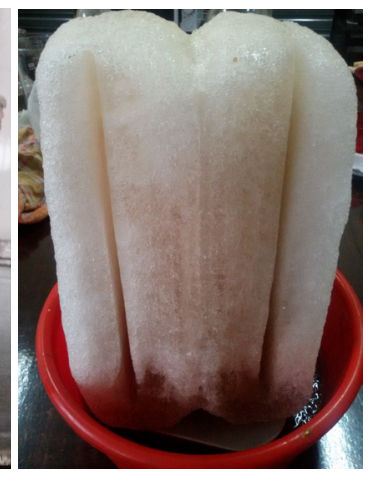

b
Fig. 9. The structure of the block of ice when concentrating pomegranate juice with an initial concentration of $X=37 \%$ : $a$ - before separation; $b$ - after separation

Research indicates the prerequisites for effective separation of the block of ice in the range of working concentrations of pomegranate juice. 
The results of studying the kinetics of the separation process are shown in Fig. 10.

Analysis of the results on the kinetics of separation allows to draw the following conclusions:

- separation process can be controlled;

- it is advisable to fractionate the effluents and direct them for further concentration;

- organization of separation at zero ambient temperatures allows maintaining the structure of the solid phase and almost completely evacuating juice from the ice volume (Fig. 9, $b$ ) without melting.

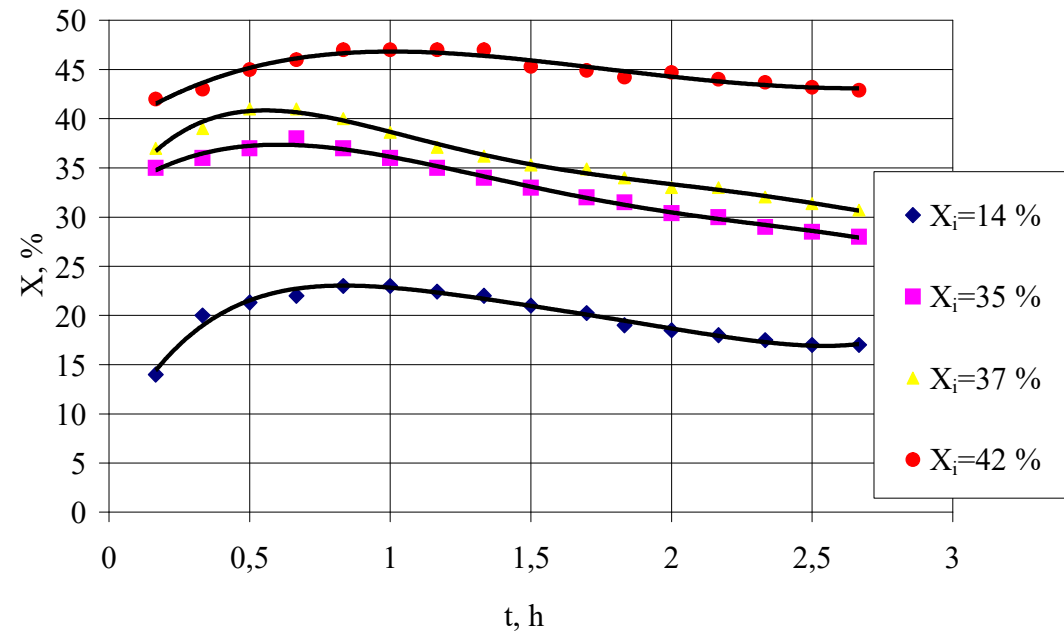

Fig. 10. Change in the concentration of dry matter in wastewater at different initial concentrations of pomegranate juice

\section{4. Generalization of experimental modeling results}

The processing of the experimental database begins with the calculation of the mass transfer coefficient:

$$
\beta=\frac{V_{i}}{F_{i} \cdot\left(x_{c r}-x_{c}\right)}, \mathrm{M} / \mathrm{c}
$$

where:

$-V_{\mathrm{i}}$ - ice volume;

$-F_{\mathrm{i}}-$ ice block surface area;

$-x_{\mathrm{cr}}-$ cryoscopic concentration of juice;

$-x_{\mathrm{c}}-$ current concentration of juice.

The Sherwood number is found:

$$
\mathrm{Sh}=\frac{\beta \cdot l}{D}
$$

where $l$ - width of the ice block; $D$ - diffusion coefficient of dry substances into the ice block.

Hydrodynamic modes are determined by the Grashof number:

$$
G r=\frac{g \cdot\left(\frac{1}{T_{c}}\right) \cdot \Delta t \cdot h^{3}}{v^{2}},
$$

$g$ - acceleration of gravity; $T_{c}$ - temperature of the juice; $t$ - temperature difference between the juice and the phase contact surface; $h$ - height of the ice block; $v$ - viscosity of the juice.
The constraint conditions are expressed by the parametric complex K:

$$
K=\frac{\Delta}{h},
$$

$\Delta$ - thickness of the gap between the ice block and the surface.

The values of cryoscopic juice concentrations are determined experimentally, and the temperature of the phase contact surface is taken to be equal to the boiling point of freon in the channels of the crystallizer.

The analysis of the results was carried out using the methods of the similarity theory. Stratification by the parameter $K$, which is responsible for the hydrodynamic situation in the concentrator, for the formation of gravitational convective currents, is illustrated in logarithmic coordinates (Fig. 11).

Further, the dependence of the Sherwood number on the parametric complex $K$ is determined at the value of the Grashof number $10^{8}$. The slope of the dependence determines the constant $n$ in the criterion model at the number $K$. This indicator is equal to the number -0.43 .

At the next stage, the constant is determined at the number Gr. For this, the $\mathrm{Sh} / K^{-0,43}$ complex is calculated, which is expressed depending on the Gr number. As a result, a criterion model was obtained:

$$
\mathrm{Sh}=0.36 \times \mathrm{Gr}^{0.12} \times K^{-0.43} \text {. }
$$

Relation (5) allows, with an error of no more than $20 \%$, to calculate the mass transfer coefficients in the range of Grashof numbers $10^{6} \geq \mathrm{Gr} \geq 10^{10}$ and the parameter $0.02 \geq K \geq 0.55$.

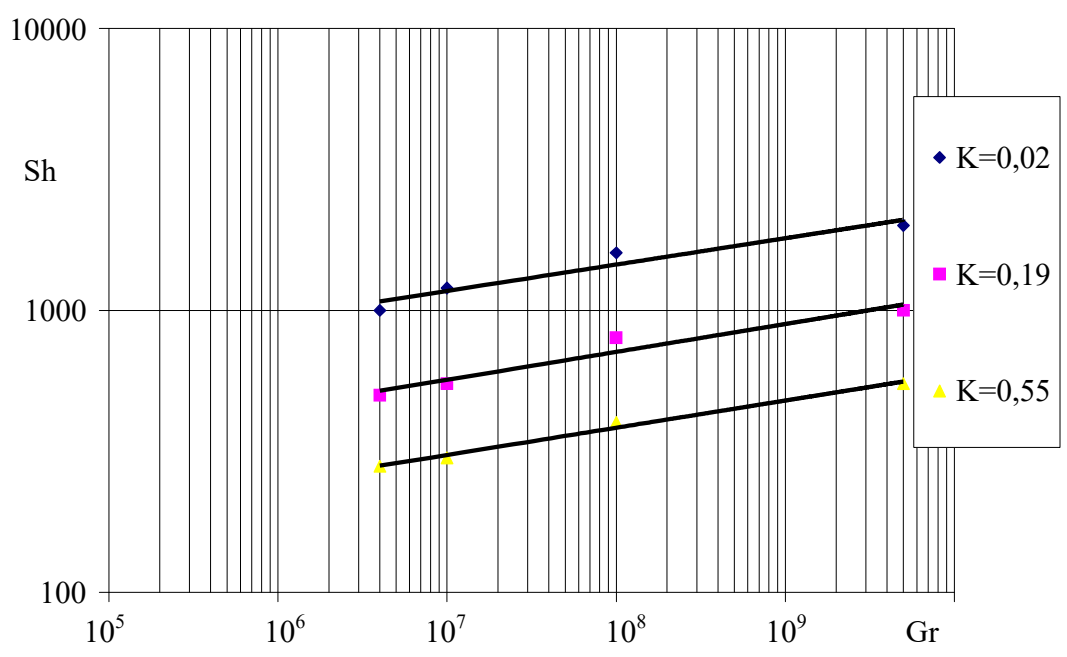

Fig. 11. Dependence of the Sherwood number on the Grashof number for different K 
ing bodies on which blocks of ice are frozen. A design feature is that the working bodies are in the form of horizontal plate modules, inside of which the refrigerant evaporates.

Studies of the BL-20 and BV-2 installations for block freezing of pomegranate juice show that:

- productivity of the installation increases. This is achieved through the effective use of the surface of the lamellar horizontal working bodies;

- degree of concentration of the solution increases. The degree of concentration of pomegranate juice is almost 1.7 times higher than that of [22] cherry juice under the same temperature conditions. The achieved concentration of pomegranate juice is $47^{\circ}$ Brix (Fig. 6), which is significantly higher than in the known devices. This is due to the fact that the use of horizontal working bodies allows to combine the directions of diffusion of soluble substances in the solution and gravitational forces and accelerate diffusion from the boundary layer into the solution;

- the mass fraction of soluble substances in the melt of the ice block decreases, which leads to a decrease in product losses. This is due to the fact that vertical channels are formed in the volume of the ice block, from which juice is more efficiently evacuated during the separation process. Organization of separation at zero ambient temperatures allows maintaining the structure of the solid phase and almost completely evacuating juice from the ice volume (Fig. 9, b) without melting.

Freezing plants are the most energy efficient. Block freezing plants guarantee the preservation of the food potential of raw materials, savings in transportation.

The volume of the BL-20 cryoconcentrator is 20 liters. The volume of the industrial block cryoconcentrator of Meiwa Co., Ltd. - 50 l. In comparison with studies [18-20] carried out on small volumes $(45-50 \mathrm{ml})$, the results presented can be effectively scaled up when creating more powerful industrial installations. Compared to [21], the studies were carried out in a wide range of temperatures.

The disadvantage of the BV-2 design is that only one side of the mold surface is used and it is difficult to assemble a system of such molds in one apparatus. Thus, the installation (Fig. 1) is limited to small capacities.

Prospects for using the developed installations consist in obtaining high-quality products with minimal energy costs:

- whey protein concentrate;

- concentrated milk;

- concentrated wine material;

- concentrated juices, extracts.

Block freezing units can be used for water treatment processes:

- post-treatment of tap drinking water;

- additional purification of water in food technologies;

- production of melt water for the production of vodka, drinks and therapeutic and prophylactic extracts;

- water desalination.

Block freezing units are effective as icemakers and can be retrofitted to produce shaped, colored ice.

\section{Conclusions}

1. The influence of the temperature of the coolant and the initial concentration of the juice on the rate of formation of the ice block has been determined. Lowering the operating temperature of the refrigeration unit promotes more intensive growth of the ice block. For the BV-2 unit, the effect of temperature on productivity is more significant than for the BL-20 crystallizer. When the temperature of the coolant decreases by 1.2 times, the productivity of the BV-2 unit increases by $27 \%$, of the BL-20 unit - by $12 \%$. This is due to the design features of the installations.

2. The nature of the change in the concentration of dry substances in the solution depends on the initial concentration of the solution and the temperature of the crystallizer. At low initial concentrations of solutions $(10 \ldots 15 \%)$, there is a sharp increase in the concentration of the solution at the final stage of freezing. The dry matter content in the juice increases by $16 \%$, which is due to the low water content in the solution. An increase in the initial concentration up to $30 . . .40 \%$ causes a smooth change in the concentration of the solution. The dry matter content of the juice is increased by $4 \%$. Its concentration is lower. The kinetics of the process corresponds to a sigmoidal curve, which correlates with studies $[9,10]$ for other juices.

3. The kinetics of the ice block separation process has been studied. There are 3 stages. At the first stage (its duration is $10 \ldots 15$ minutes), the product flows from the outer surface of the block. Actually, the diffusion boundary layer is removed. As a rule, the concentration of these effluents (boundary layer) is $2 . .3 \%$ higher than the average concentration of the solution at the current time. The second stage is characterized by an increase in effluent concentration by $6 \ldots 10 \%$. This is due to the fact that the evacuation of juice from the inner layers of the block begins. Since the temperature in the depth of the block is lower than on the surface, the concentration of juice in the capillaries of the block is also higher, it approaches the values of cryoscopic conditions. In the third stage, a monotonous decrease in effluent concentration $(2.5 \%$ /hour $)$ is observed. This happens because as the ambient temperature rises, thin layers of ice melt at the boundary, on the surfaces of the capillary channels. The melted ice dilutes the juice and lowers the effluent concentration. The higher the ambient temperature, the steeper the decrease in effluent concentration.

4. The conducted studies of the cryoconcentration process of pomegranate juice have shown that the decisive influence on the process is exerted by the force of gravity, the temperature of the product, and the geometric parameters of the ice block. This is confirmed by the analysis of the resulting model. The exponent at the number Gr (includes the product temperature) is 0.12 , the inverse dependence on the parametric complex $K$ (geometric parameters of the ice block) -0.43 .

\section{References}

1. Burdo, O. H., Kovalenko, O. O., Reminna, L. P. (2008). Pat. No. 34280 UA. Sposib otrymannia kontsentrovanykh ridkykh produktiv shliakhom vymorozhuvannia. No. u200801496; declareted: 05.02.2008; published: 11.08.2008, Bul. No. 15. Available at: https:// uapatents.com/3-34280-sposib-otrimannya-koncentrovanikh-ridkikh-produktiv-shlyakhom-vimorozhuvannya.html

2. Müller, M., Sekoulov, I. (1992). Waste Water Reuse by Freeze Concentration with a Falling Film Reactor. Water Science and Technology, 26 (7-8), 1475-1482. doi: https://doi.org/10.2166/wst.1992.0591 
3. Miyawaki, O. (2001). Analysis and Control of Ice Crystal Structure in Frozen Food and Their Application to Food Processing. Food Science and Technology Research, 7 (1), 1-7. doi: https://doi.org/10.3136/fstr.7.1

4. Zambrano, A., Ruiz, Y., Hernández, E., Raventós, M., Moreno, F. L. (2018). Freeze desalination by the integration of falling film and block freeze-concentration techniques. Desalination, 436, 56-62. doi: https://doi.org/10.1016/j.desal.2018.02.015

5. Qin, F. G. F., Ding, Z., Yuan, J., Jiang, R., Huang, S., Yin, H., Shao, Y. (2019). Visualization data on concentrating apple juice with a trinitarian crystallization suspension freeze concentrator. Data in Brief, 25, 104155. doi: https://doi.org/10.1016/j.dib.2019.104155

6. Ding, Z., Qin, F. G. F., Yuan, J., Huang, S., Jiang, R., Shao, Y. (2019). Concentration of apple juice with an intelligent freeze concentrator. Journal of Food Engineering, 256, 61-72. doi: https://doi.org/10.1016/j.jfoodeng.2019.03.018

7. Sánchez, J., Ruiz, Y., Raventós, M., Auleda, J. M., Hernández, E. (2010). Progressive freeze concentration of orange juice in a pilot plant falling film. Innovative Food Science \& Emerging Technologies, 11 (4), 644-651. doi: https://doi.org/10.1016/j. ifset.2010.06.006

8. Petzold, G., Niranjan, K., Aguilera, J. M. (2013). Vacuum-assisted freeze concentration of sucrose solutions. Journal of Food Engineering, 115 (3), 357-361. doi: https://doi.org/10.1016/j.jfoodeng.2012.10.048

9. Bayindirli, L., Özilgen, M., Ungan, S. (1993). Mathematical analysis of freeze concentration of apple juice. Journal of Food Engineering, 19 (1), 95-107. doi: https://doi.org/10.1016/0260-8774(93)90063-p

10. Nonthanum, P., Tansakul, A. (2008). Freeze concentration of lime juice. Maejo International Journal of Science and Technology, 1, 27-37. Available at: http://www.mijst.mju.ac.th/vol2/s27-37.pdf

11. Vuist, J. E., Linssen, R., Boom, R. M., Schutyser, M. A. I. (2021). Modelling ice growth and inclusion behaviour of sucrose and proteins during progressive freeze concentration. Journal of Food Engineering, 303, 110592. doi: https://doi.org/10.1016/j. jfoodeng.2021.110592

12. Firuzi, M. R., Niakousari, M., Eskandari, M. H., Keramat, M., Gahruie, H. H., Mousavi Khaneghah, A. (2019). Incorporation of pomegranate juice concentrate and pomegranate rind powder extract to improve the oxidative stability of frankfurter during refrigerated storage. LWT, 102, 237-245. doi: https://doi.org/10.1016/j.lwt.2018.12.048

13. Hegazi, N. M., El-Shamy, S., Fahmy, H., Farag, M. A. (2021). Pomegranate juice as a super-food: A comprehensive review of its extraction, analysis, and quality assessment approaches. Journal of Food Composition and Analysis, 97, 103773. doi: https:// doi.org/10.1016/j.jfca.2020.103773

14. Azeredo, H. M. C., Morrugares-Carmona, R., Wellner, N., Cross, K., Bajka, B., Waldron, K. W. (2016). Development of pectin films with pomegranate juice and citric acid. Food Chemistry, 198, 101-106. doi: https://doi.org/10.1016/j.foodchem.2015.10.117

15. Dhumal, S. S., Karale, A. R., More, T. A., Nimbalkar, C. A., Chavan, U. D., Jadhav, S. B. (2015). Preparation of pomegranate juice concentrate by various heating methods and appraisal of its physicochemical characteristics. Acta Horticulturae, 1089, 473-484. doi: https://doi.org/10.17660/actahortic.2015.1089.65

16. Icier, F., Yildiz, H., Sabanci, S., Cevik, M., Cokgezme, O. F. (2017). Ohmic heating assisted vacuum evaporation of pomegranate juice: Electrical conductivity changes. Innovative Food Science \& Emerging Technologies, 39, 241-246. doi: https://doi.org/10.1016/ j.ifset.2016.12.014

17. Maskan, M. (2006). Production of pomegranate (Punica granatum L.) juice concentrate by various heating methods: colour degradation and kinetics. Journal of Food Engineering, 72 (3), 218-224. doi: https://doi.org/10.1016/j.jfoodeng.2004.11.012

18. Putnik, P., Kresoja, Ž., Bosiljkov, T., Režek Jambrak, A., Barba, F. J., Lorenzo, J. M. et. al. (2019). Comparing the effects of thermal and non-thermal technologies on pomegranate juice quality: A review. Food Chemistry, 279, 150-161. doi: https://doi.org/10.1016/ j.foodchem.2018.11.131

19. Petzold, G., Moreno, J., Lastra, P., Rojas, K., Orellana, P. (2015). Block freeze concentration assisted by centrifugation applied to blueberry and pineapple juices. Innovative Food Science \& Emerging Technologies, 30, 192-197. doi: https://doi.org/10.1016/ j.ifset.2015.03.007

20. Petzold, G., Orellana, P., Moreno, J., Cerda, E., Parra, P. (2016). Vacuum-assisted block freeze concentration applied to wine. Innovative Food Science \& Emerging Technologies, 36, 330-335. doi: https://doi.org/10.1016/j.ifset.2016.07.019

21. Khajehei, F., Niakousari, M., Eskandari, M. H., Sarshar, M. (2015). Production of Pomegranate Juice Concentrate by Complete Block Cryoconcentration Process. Journal of Food Process Engineering, 38 (5), 488-498. doi: https://doi.org/10.1111/jfpe.12179

22. Ovsyannicov, V. Yu., Kondrateva, I. I., Bostynets, N. I., Denezhnaja, A. N. (2015). Batch-wise process of cherry juice freeze concentration. Vestnik mezhdunarodnoy akademii holoda, 1, 4-8. Available at: https://cyberleninka.ru/article/n/issledovanieprotsessa-tsiklicheskogo-kontsentrirovaniya-vishnevogo-soka-vymorazhivaniem 